\title{
¿Qué pasa con la quimioprofilaxis de la tuberculosis con isoniazida?
}

\author{
What about chemoprophylaxis of \\ tuberculosis with isoniazid?
}

\section{Amador Carcelén-Bustamante}

Director de Acta Médica Peruana

La tuberculosis sigue siendo una causa importante de mortalidad en el mundo entero. Se ha estimado que en año 2011 fallecieron 1400000 pacientes.

Las estrategias diseñadas para su control incluyen diagnosticar y tratar a los enfermos que diseminan los gérmenes y a sus contactos infectados que aún no han desarrollado la enfermedad, para así cortar la cadena epidemiológica. Estos contactos se caracterizan por ser asintomáticos, con radiografía de tórax normal, pero con reacción cutánea positiva al PPD, y tienen la denominada tuberculosis latente, condición que conlleva la posibilidad de ser reactivada y llegar a la enfermedad tuberculosa. Como estos contactos asintomáticos tienen una muy baja concentración bacilar, es razonable tratarlos solo con isoniazida (INH), una droga bactericida, en un tratamiento denominado profilaxis secundaria.

Bajo estas premisas, Constock, ${ }^{1,2}$ primero en 1960 y posteriormente en 1967, publicó sus estudios en esquimales en Alaska, en los que identificó y trató a los pacientes y a sus contactos, estos últimos solo con $\mathrm{INH}$. Con este tratamiento obtuvo un éxito muy considerable; en un periodo de seis años bajó la incidencia de tuberculosis en $55 \%$ y la llevó a un nivel comparable al de Estados Unidos continental.

Churchyard $^{3}$ publicó un reciente estudio sobre prevención de tuberculosis en mineros de oro en Sudáfrica, en el cual dispensaron INH por seis meses o más, según la mina donde trabajaban. El grupo de intervención incluyó 7561 pacientes y el control, 6397, con un total de 13958 pacientes. La intervención no

\section{Referencias bibliográficas}

I. Comstock GW, Woolpert. Isoniazid prophylaxis among Alaskan Eskimos: a progress report. Am Rev Respir Dis 1974; I 10:195-7.

2. Comstock GW, Ferebee. Isoniazid prophylaxis in Alaska.Am Rev

redujo la incidencia de tuberculosis (tasa de 3,02 por 100 personas año versus 2,95 en los controles). Si se analizan las tasas al primer año (1,10 personas año en el grupo tratado versus 2,91 en el grupo control), se observa que son protegidos durante el tratamiento, pero la protección se pierde rápidamente.

Cuando se analiza la metodología empleada por Churchyard, se encuentra que no se utilizó PPD en ningún caso, se estimó que de hecho era positivo por la muy alta incidencia de tuberculosis en estos grupos de trabajadores. El diagnóstico de tuberculosis activa se hizo con una radiografía de tórax y un examen de esputo; de modo que es posible que algún caso positivo haya sido considerado negativo y tratado con INH como agente único.

En el estudio de Churchyard, $12,5 \%$ de los mineros reportaron haber tenido previamente tuberculosis; $13,6 \%$, ser positivos para $\mathrm{VIH} ; 2,7 \%$ reportaron haber recibido previamente terapia antirretroviral; 2,6\% tenían silicosis definida y $0,5 \%$ reportaron haber recibido, antes o actualmente, terapia con $\mathrm{INH}$. Finalmente, 40 mineros compartían horas de compañía durante el trabajo y además eran alojados en hoteles.

Es preciso, pues, que se acepte que la INH no protege a los pacientes que pueden tener infección por $\mathrm{VIH}$ o silicosis y tuberculosis activa, como este grupo de mineros. Asimismo, es necesario pensar en otros regímenes de tratamiento, en especial, en zonas de alta incidencia de resistencia a la INH. Se conoce ya algunos datos con rifapentina y nuevas drogas como bedaquilina.
Respir Dis 1967;95:935-43.

3. Churchyard et al.A trial of mass isoniazid preventive therapy for tuberculosis control. N Engl J Med. 2014;370:293-392. 